\title{
The mechanical monster and discourses of fear and fascination in the early history of the computer
}

\author{
Hannah Grenham (1) ${ }^{1 凶}$
}

This article explores the concept of monstrosity in relation to the development of digital computers during the 1950s in the United States. Discourse analysis of public representations of early digital computers reveals a consistent appropriation of monstrosity as a metaphor to capture cultural fears of human-mechanical hybridity and technological autonomy. Deconstructing the development and application of this metaphor provides valuable insight into cultural attitudes about computers during this period. Through this analysis, the development of the computer appears as simultaneously following its own unique trajectory while also coinciding with broader trends in the cultural histories of new technologies. In particular, the example of the computer epitomises a dichotomy of fear and fascination, which is frequently seen in response to new technologies. Specific examples of early computers that are considered include ENIAC, WHIRLWIND, and UNIVAC. The public representation of and responses to each of these machines demonstrates a fundamental division between admiration at their technical application and concern over their apparently unlimited potential. This dichotomy is identified particularly through examination of contemporaneous popular cultural representations. Images of monstrosity are also shown to be consistent in these public representations, with rhetoric focusing in particular on anthropomorphic machines and human-mechanical hybridity. As a result, the fears of scientific creation encapsulated by Shelley's depiction of Frankenstein's monster can be seen to play out over a century later through the 'mechanical monsters' of the 1950s United States.

\footnotetext{
${ }^{1}$ Bishop Grosseteste University, Lincoln, UK. ${ }^{凶}$ email: hannah.grenham@bishopg.ac.uk
} 


\section{Introduction}

he notion of hybridity lies at the heart of many fictional monsters. From Shelley's Frankenstein to Dick's Do Androids Dream of Electric Sheep? the blurring of lines between humanity and mechanisation has been a trope for engendering intrigue and horror in readers of fiction. However, the concept of the mechanical-human hybrid has not been restricted solely to worlds of fiction and fantasy. On the contrary, new technologies have historically triggered similar dichotomous reactions, positioned delicately between the excitement of possibility, the mystique of the unknown, and the fear of usurpation. In particular, the development of the digital computer in the twentieth century created a conflict in cultural attitudes due to its enormous potential as a scientific tool that might be capable of 'thinking' on its own. The concept of hybridity between human and machine is even encapsulated in the etymology of the term 'computer'. Traditionally the job description of humans operating calculating machines, the twentieth century saw the term shift into a new concept: a descriptor of the machines themselves (Evans, 2018, p. 9). Furthermore, the computer adopted a position in the public consciousness as a new, unknown, and largely incomprehensible technological marvel. This paper will argue that while technologies have historically shared properties of the monstrous, the interactivity and potential hybridity of the computer cast it as a uniquely mechanical monster in its early years. It will also suggest that this perception of the computer was more significant in shaping cultural attitudes towards it than its practical applications.

The paper explores the development of the computer as a cultural object through analysing public responses to the first digital computers in the 1950s United States (US). It will focus specifically on the US as an example at the forefront of digital computing, although it should be acknowledged that computing developments occurred globally in a multitude of ways and often simultaneously. Although these computers were predominantly reserved for military, scientific, or industrial purposes, they also became known to a wider popular audience through cultural representations. For example, the ENIAC computer received a public launch in 1946 (Martin, 1993), while the US Navy machine WHIRLWIND appeared on a primetime television broadcast of See It Now in 1951 (CBS, 1951). The UNIVAC computer, meanwhile, not only had a starring role in CBS's election night coverage in 1952 (Alfred, 2010; Henn, 2012), but also featured in popular cartoons such as the Looney Tunes series Merrie Melodies (Warner Bros., 1952). These examples will be analysed to identify how the computer aligned with broader cultural representations of technology, through engagement with themes including monstrosity, technophobia, and cyborgism.

The paper will initially establish theoretical contexts of the relationship between humanity, technology, and monstrosity. In particular, it will focus on the conception of monstrosity devise"d by Carroll (1987) and the notion of technicity as co-constitutional, as posited by thinkers including Latour (2002) and Hayles (2012). It will then consider the examples of three early American computers-ENIAC, UNIVAC, and WHIRLWIND-to explore how they aligned with, or diverged from, these established themes. The analysis draws on the idea of technological sociologists Oudshoorn and Pinch $(2005$, p. 2) that technologies are best understood in terms of their "context of use"-the society and the web of other artefacts within which technologies are always embedded'. Through this concept, Oudshoorn and Pinch (2005) suggest the ways technologies are used by and integrated into society help to construct their popular identity. As such, the paper will analyse the cases of these early computers by identifying and evaluating their perceived contexts of use in US society. The discourse used in cultural representations of computers will be analysed to understand how the public identity of the machines was established. This requires an externalist approach to understand the connections between the computer, contemporary American society, and broader cultural attitudes towards technology. The 'laws' of technology proposed by Kranzberg (1986) are particularly relevant; specifically, the suggestion that 'technology is a very human activity-and so is the history of technology' (Kranzberg, 1986, p. 557) underscores the importance of exploring cultural attitudes towards the computer as part of its development. This approach is also recommended by Staudenmaier (1984), who suggests that technological developments cannot be easily divorced from cultural context. In this sense, the computer cannot be considered a 'culturally neutral artefact' (Staudenmaier, 1984, p. 710). This externalist approach will help to identify more clearly how issues relating to technology and broader cultural attitudes overlapped in the early history of the digital computer.

Edwards (1996) has provided an example of how the computer may be treated as a cultural product through an analysis of contemporary discourse, identifying two discourses surrounding computers as part of Cold War technical proliferation. He terms the first of these 'closed-world discourse' (Edwards, 1996, p. 7), defined as the language, rhetoric, and metaphor that developed around computers in discussions on Cold War strategy. $\mathrm{He}$ compares the rhetoric used regarding this technology to that used in discussions of national computerised systems and Cold War defence strategies, and in doing so highlights important commonalities such as cybernetics, artificial intelligence, and cognitive psychology. The second discourse Edwards (1996, p. 21) identifies is a 'cyborg discourse', characterised as the language that emerged to describe interactions between humanity and technology. This discourse was particularly focused on psychological and cognitive elements of computer technology. The combined result of these co-existing discourses, Edwards (1996, p. 161) argues, was a particular focus on the concepts of command and control in terms of computer development and the Cold War. In terms of this paper, therefore, Edwards' work offers a model of establishing a connection between discourse and social context as a way of understanding cultural attitudes towards specific technologies.

Conceptualising monsters and machines. To understand how technology may be conceptualised as monstrous, it is useful to consider the qualities of monstrosity. Diverging from the Aristotelian conception of monstrosity as 'a mistake of nature', Carroll (2004, p. 40) casts it instead as a 'violation of the natural order'. This implies an element of intention on the part of the monster or creator, as opposed to an organic aberration of the natural order. Moreover, there appears to be a connection between conceptions of monstrosity and contemporary science, as the natural order is determined by boundaries of scientific possibility (Carroll, 2004, p. 40). As science evolves and extends these boundaries, what constitutes the natural follows suit. It is not surprising that the 'Overreacher Plot' has been identified as a popular trope in horror and science fiction, in which the figure of the scientist, in possession of hidden knowledge, extends the boundaries of the natural and thereby creates a monster (Carroll, 2004, p. 118). Carroll's (1987, p. 51) deconstruction of 'art-horror' in response to monsters is also illuminative for understanding cultural responses to technology. In 'The Nature of Horror' (Carroll, 1987), monsters are characterised as beings that trigger an affective response of simultaneous fear and disgust. The fear originates from an evaluative belief that the being poses a threat to the subject, while disgust comes from a sense of impurity, as defined by Douglas (2002). It is the interstitiality of monsters, 
therefore, which makes them appear impure; they occupy a liminal space between two states of being. Hybrid beings, such as Frankenstein's monster or Count Dracula, violate the established categories of nature, and it is this hybridity which causes the combined responses of fear and disgust. Finally, it is also useful to consider the conception of monstrosity as a social construction contingent upon the ideas and values of a society. Lawrence (2015) suggests the etymology of the term 'monsters' derives from monstrare - 'to demonstrate' - and monere- 'to warn'. Consequently, she argues monsters can be considered demonstrative in that they reveal something about the society by which they are constructed (Lawrence, 2015). In particular, it may be suggested that monsters provide a means for society to confront concepts which may be culturally or psychologically challenging.

These definitions help to illustrate what may be perceived as monstrous about technologies such as computers. Studies of horror and science fiction highlight a frequent overlap between the two genres, with robots often cast as potential monsters of the latter (Carroll, 2004, pp. 13-14). The fear of the scientist as a new 'elite' and possessor of hidden knowledge was an identifiable aspect of Cold War technological progress. Commentator Ben Baruch Seligman (1966, p. 304) warned that scientists were becoming more like 'a shaman, a superior being' and subsequently identified 'the problem of controlling the scientist'. Meanwhile President Eisenhower (1961) warned explicitly about the potential authority of the 'military-industrial complex':

In holding scientific research and discovery in respect, as we should, we must also be alert to the equal and opposite danger that public policy could itself become the captive of a scientific-technological elite.

The concept of the scientific expert as a power-broker in policy was perceived as alarming to those who could be isolated due to ignorance of the technology, especially politicians who had traditionally monopolised socio-political control. The idea of machines that could think for themselves represented an even greater potential power shift, which could threaten the reduction or even complete loss of human autonomy.

It is also possible to see how technologies like computers might be conceptualised as monstrous through affective responses they may trigger. In the 1950s US automation represented a potential existential threat not only to policy-makers but to workers, undermining their positions and offering cheap replacements for labour. This was not relegated solely to industrial workers; the traditional role of housewives was potentially threatened by domestic automation such as washing machines and dishwashers (Cowan, 1985). It could be argued that the perceived imposition of technology on traditional categories of work could lead to broader fear that such technologies represented a threat to established patterns of day-to-day life. Moreover, technologies could be identified as existing within the interstitial space characterised by both Carroll (1987) and Douglas (2002) as a symbol of impurity. Computers, as technologies that appeared to think for themselves and characterised with anthropomorphic imagery, could be cast as violating the natural order. As such, it is not hard to see how computers may have triggered both fear and disgust, albeit without explicit recognition of these emotions.

Theoretical conceptions of monstrosity also provide insight into why technologies have typically inspired fascination as well as fear. Lawrence (2015) highlights historical enthusiasm for the exoticism and mystique of monsters, exemplified by public displays of mythical creatures like mermaids and dragons. For Carroll (2004, p. 187), the pleasure of art-horror is rooted in the viewer's curiosity; they seek the revelations inculcated through direct engagement with the monstrous. Feagin (1992), meanwhile, suggests the fascination with horror originates from the pleasure of feeling fear and disgust; the affective response wrought by the monstrous is both the end and the means. It is possible to identify parallels with historical responses to technologies. Even those technologies that posed the potential for mass destruction, such as nuclear technologies, were greeted by both existential dread and mass excitement. For example, the transformation of Las Vegas into 'Atomic City' from the 1940s saw tourists flock to watch atomic testing at the Nevada Test Site, hosted in Dawn Bomb Parties with atomic-themed cocktails (Hendricks, 2018, p. 265). Such responses spoke not just to a lack of understanding about the extent of the dangers of nuclear science, but also represented curiosity and excitement with power of the unknown.

Given this paper's focus on interactions between computers and contemporary culture of the 1950s US, it is important to consider conceptions of the relationship between technology and humanity. Technology is a broad term popularly considered to encompass tools designed to assist humanity in achieving specific objectives. However, an exploration of conceptual theories about the relationship between technology and its users-or 'technicity'-suggests this definition requires a more nuanced perspective. By doing so, it is possible to explore specific examples of early computers in the context of their position within this relationship. The traditional understanding of the relationship of technology to humanity is that the former operates primarily as a tool. This is what Heidegger $(1977$, p. 5) has referred to as the 'instrumental' definition of technicity; technology provides a means to an end determined by the operator. The instrumental definition implies the possibility of mastery over the technology and thereby places it in a position of subservience to the user. This conception of technology perhaps falls most closely in line with popular conceptions of technology in the 1950s US.

Technological determinists have cast technicity in distinctly different terms. From this perspective, technology is the master in the relationship, moving from automated to autonomous. Ellul (1964) argues that technique-incorporating technology-influences all areas of society, describing humanity as 'content to participate in technical progress, to accept whatever direction it takes automatically, and to admit its autonomous meaning' (Ellul, 1962, p. 399). In this conception, technology is cast as an autonomous force with a primarily constructive influence upon society. The argument is similar to Winner's $(1978$, p. 100) 'technological imperative', in which technologies reconstruct societies in a one-directional relationship. Winner's (1986, p. 11) conception of technicity explicitly characterises human beings as 'operating parts' within a technological system, rather than subjects with their own autonomy and agency. In this way, technological determinism offers a different conceptualisation of the relationship between technology and its users, placing the technology in the position of mastery.

For the purposes of understanding responses to the computer as monstrous, however, the instrumental and determinist positions are perhaps both too reductive. Instead, it may be more useful to consider conceptualisations of technicity as transformative or even co-constitutional. Latour (2002) has argued that technology does not operate simply as means to an end but rather has transformational properties. Using the example of a hammer transforming its operator's hand into a being with new possibilities, Latour (2002, pp. 249-250) suggests that technology operates with its user to create something entirely new. From this perspective, technology is not a tool to be mastered by humanity, but neither is it cast as a solely determining force, as the operator retains a level of agency. In this sense, the master-servant dynamic in technicity is rendered null, and may be understood beyond conceptions of cause-andeffect, incorporating more nebulous concepts such as intention, 
morality, and belief on the part of the user. Some historians have identified ways in which technologies have created new practices, which subsequently become normalised as cultural processes. A relevant example is Kirschenbaum's (2016) exploration of the development and integration of the word processor. In his examination of word processing, Kirschenbaum (2016) argues that while the concept represented a new way of approaching the traditional task of writing in the 1970s, within a decade this new process had become normalised. In this way, Kirschenbaum's work demonstrates a historical example of the phenomenon identified by Latour, that technologies may respond to a human need, but in turn transform everyday practices. This emphasises the importance of understanding early responses to computers as new technologies in the 1950s, before they became more normalised within American society.

The separation of technology from instrumental definitions of functionality also aligns with Heidegger's (1977) exploration of the 'essence' of technology. This is something quite separate from technology as a tool; instead, it incorporates modes of thinking and reasoning behind the creation and use of the tool. As such, technology is cast by Heidegger as revelatory; it brings forth a creation through its engagement by an operator. It is particularly relevant to consider Heidegger's (1977, p. 16) concept of modern technology as not offering a 'bringing-forth' so much as a 'challenging-forth', as this perspective casts technologies and the natural world primarily in terms of material possibility. As a result, the relationship between humanity and technology may be characterised as even more indeterminate. The blurring of lines between materiality, intention, and humanity offers an alternative perspective to understanding the relationship between the public and early computers, because it recasts the machines not as tools, but as symbols of the creation of new possibilities.

Another conception of technicity that casts the relationship between humanity and technology as co-constitutional is Hayles' (2012) notion of technogenesis. Hayles (2012) argues technology occupies a pivotal role in the development of human culture, with no clear ontological distinction between humanity and its technological environment. For example, the development of technologies designed to prolong life-expectancy is inevitably intertwined with social forces of politics and economics. Furthermore, Hayles (cited in Pötzsch, 2014) suggests a posthumanist understanding of technology enables 'a new look at the boundaries between what counts as human, animal, machine, or object'. From this perspective, it may be possible to reinterpret the relationship between early computers and humanity as one that challenged established boundaries like no previous technologies. As a result, it appears unsurprising that computers may have been perceived as monstrous due to their potential for hybridity. For this reason, it is also worthwhile to consider conceptions of technicity in which technology is truly embodied not just culturally, but within the human body itself. Connections may be drawn with Haraway's (1985) seminal work on cyborgism, which offers an embodied conception of technicity. Haraway (1985, p. 65) posits the cyborg is a 'hybrid of machine and organism, a creature of social reality as well as a creature of fiction'; in this sense, it fits neatly with Carroll's conception of the science fiction monster. Consequently, this conception casts technicity as ultimately ambiguous; previously established boundaries between the two categories are not only crossed but erased. For some thinkers, this transhumanist movement towards a true human-mechanical hybrid represents the improvement of the human condition (Pilsch, 2017). From this perspective, the notion of an increasingly ambiguous relationship may be considered as an evolutionary development, erasing completely the concept of differentiation between human and machine.
Considering these different conceptions of technicity, it is possible to identify why the computer may have been perceived to pose a particularly 'monstrous' threat in the 1950s. Given the prevalence of an instrumental view of technology, it represented one of the first public examples of technology that was more closely related to conceptions of technicity as co-constitutional. Analysing the representation of the relationship between early computers and their operators will be essential to understand the impact of the discourse of fear and fascination in sociocultural terms.

Before analysing specific examples of early computers, it is worth considering how the contemporary technological context of the Cold War US had already raised questions around technicity and technophobia. Technologies in this period frequently triggered conflicted responses among Americans; a prominent example of such duality was nuclear proliferation. Since the nuclear arms race had become public in 1945, this technology was cast in American media simultaneously as the potential destroyer and possible saviour of global democracy (Atomic Heritage Foundation, 2019). This potential caused the bomb to be likened to a monster, with the Pittsburgh Post-Gazette (1945) calling it 'a monstrous thing, this secret weapon'. It demonstrated how invention and morality could not easily be separated; as with Latour's hammer, the US became an entirely new being with the possession of this new technology. Subsequent forecasts of 'technological acceleration' in the wake of the bomb envisaged an apocalyptic future, with commentator Hart (1946, pp. 278-279) stating that 'scientists are now able to produce bombs of which three, if properly placed, would wipe out not only our cities, but every man, woman, and child in the United States'. Simultaneously, it was equally apparent that nuclear superiority was intrinsically connected to national supremacy. For example, when news of the hydrogen bomb emerged, the St Petersburg Times assured its readers that the most important fact to be borne in mind by the public is that America is now ahead of Soviet Russia' (Lawrence, 1953). The atomic discourse demonstrated how technological prowess was frequently equated to geopolitical power in the Cold War. In a nation in which the technological sublime played a key role in cultural developments, the emergence of superior technologies could never be a neutral development.

Even discourse surrounding new technologies for which the context of use lay in the domestic sphere demonstrated polarisation. The electrification of domestic tasks was heralded as a means of increasing efficiency within a home, with General Electric's 1954 campaign featuring Ronald Reagan calling on Americans to 'Live Better-Electrically!' (Kellner, 2019). The rhetoric used by the campaign to promote domestic technologies drew heavily on the fact that human tasks could now be performed by machines: 'Modern folks have learned to save their time and energy too. You don't have to work and slave: let electricity do it for you!' (General Electric Theatre, 1957). However, the perception of technology taking on human tasks in the workplace raised fears of workers being replaced by machines. Commentator Hal Boyle voiced fears that the proliferation of mechanisation would render humanity functionless, warning against 'gadgets of all kinds that make men more comfortable but wean them from nature' (Boyle, 1949, p. 14). 'And what is [the machine age] doing?' Boyle (1949, p. 14) asked in the Evening Independent. 'It is gradually making [man] unnecessary in the world-by taking over his functions.' Boyle's words parallel a co-constitutional relationship with technology, in which the categorisations between machine and operator become blurred. Furthermore, they echo the 'Overreacher Plot' highlighted by Carroll (2004, p. 118) as a common trope within horror 
fiction, in which creations begin to challenge and usurp their masters.

The development and proliferation of the computer within this context ensured that it was not a culturally neutral object. It was a particularly complex technology because it had an increasingly prominent cultural presence even though its context of use was primarily military, industrial, and scientific. It also contributed to the success or failure of geopolitical technological projects such as the nuclear programme and later the Space Race. As such, its importance as a Cold War technology was undeniable. Simultaneously, however, the challenges that it posed to instrumental conceptions of technology meant it also appeared to present a potential threat to the work, society, and life of ordinary Americans. As the following examples will indicate, this resulted in conflicting discourses around early computers, characterised by a significant dichotomy between simultaneous fear and fascination.

\section{Early American computers: ENIAC, UNIVAC, and WHIRLWIND}

The computer as hybrid. Public representations of the earliest computers in the US were characterised by a recurrent theme of anthropomorphism in the discourse, ranging from naming and treating them as colleagues to images of electronic brains. In cases of the former, the intention was typically to normalise the machines and make them palatable for an audience unfamiliar with such technologies. However, it may also have had the effect of feeding into conceptions of the computer as a human-machine hybrid, thereby positioning it within the interstitial space that Carroll (1987) characterises as monstrous.

The characterisation of the digital computer as an electronic brain emerged early in the public discourse. The most prolific of these early machines was the Electronic Numerical Integrator and Calculator (ENIAC), developed as part of the American nuclear programme. From the outset, ENIAC was highly publicised in the press, receiving a public launch at the Moore School of Engineering in 1946 (Martin, 1993). It was lauded particularly for its speed, with the New York Times heralding it 'the new electronic speed marvel' and engineer Eckert declaring 'the new [era] of electronic speed is on the way' (Kennedy, 1946, p. 1, p. 16). The press highlighted the technical capabilities of the machine to readers, focusing predominantly on speed and power. This underscored the context of use of the computer as primarily scientific; it was clear that this cutting-edge technology was to be operated only by experts who could fully understand its technical capabilities. However, these technical details were consistently accompanied by language and imagery that implied a more complex relationship between computers and humanity. Martin (1993) has compiled a comprehensive report of the rhetoric employed by media in response to ENIAC. Much of this rhetoric associates it directly with human brains: the Washington News called ENIAC an 'electronic super-brain' (cited in Martin, 1993, p. 126), the Boston Herald named it 'Mechanical Einstein' (Associated Press, 1946), and the Los Alamos Times even referred to it as 'a mathematical Frankenstein' (cited in Martin, 1993, p. 132). The echoing of Shelley's tale of a scientific creation imbued with increasing autonomy demonstrates an early connection to the theme of monstrosity by casting the computer as a hybrid machine that could seemingly think for itself. The image had staying power; four months after the public launch, the magazine Mechanix Illustrated (1946) featured an article on ENIAC entitled 'The Army Brain', with an accompanying image of ENIAC literally superimposed over a drawing of a human brain. Through such imagery, the computer appeared to embody the concept of Turing's thinking machine (Dormehl, 2016) and to represent the realisation of futurist predictions such as Wells' (2016) 'World Brain' from the 1930s.

In contemporary science fiction, too, the image of the electronic brain proliferated. In 1950, Vonnegut published the short story 'EPICAC' in Collier's Weekly, a story that featured the eponymous computer 'falling in love' with a human as a result of writing love poems. Unable to realise its feelings, EPICAC ultimately terminates itself. Vonnegut's story toyed with the notion of a computer that was more human than machine; indeed, the unnamed narrator states that 'You can call him a machine if you want to. He looked like a machine, but he was a whole lot less like a machine than plenty of people I could name' (Vonnegut, 1950, p. 118). The language directly contrasts characterising the computer as object and subject, with the officials using the pronoun 'that' while the narrator chooses 'who'. In doing so, Vonnegut (1950) captures the liminality of the computer as existing somewhere between established boundaries, while also placing limitations on it; the machine is capable of feeling love but cannot be loved in return. In a later interview, Vonnegut reiterated his view of the close connection between computer technology and human brains, referring to the latter as 'two-bit computers' (cited in Playboy, 1973).

The association of computers as electronic brains encapsulates the 'embodied' relationship of technology characterised by Hayles (2012) and Haraway (1985). In such representations, the computer appears more like a feat of biotechnology than mechanical engineering; it is cast as cyborgian, rejecting previously established boundaries between human and machine. This concept was not a new one; Wells' (2016) 'World Brain' had already established the idea of a machine that could store and provide knowledge akin to a human brain. ENIAC perhaps represented one of the first realisations of this concept, with the prevalence of the image of the electronic brain in the discourse surrounding it characterising the computer as more cyborgian than instrumental. It was presented as a hybrid 'magic brain' that, unlike more familiar technologies at the time, existed somewhere between man and machine (as cited in Gleick, 2011, p. 239). The anthropomorphism inherent in the rhetoric and imagery surrounding ENIAC, therefore, implies an anxiety about the nature of the relationship between man and this new machine. It crossed established categorical boundaries between the human and the mechanical, thereby appearing as impure and interstitial. In this sense, the computer as an electronic brain may have triggered an unconscious yet affective response of disgust, as characterised by Carroll (1987), thereby characterising it subconsciously as monstrous.

The image of the disembodied brain also reflected another trend within popular science fiction. Frequently, the existence of a brain isolated from the human body, often kept alive by technological means, represented a transhumanist interest of its creator in moving towards a human-mechanical singularity to improve the human condition. For example, in The Brain that Wouldn't Die (Green, 1962), a prime example of the Overreacher Plot, scientist Bill Cortner seeks to extend the life of his girlfriend by preserving her brain mechanically. However, the disembodied brain also plays on the affective responses of fear and disgust to be presented as a symbol of horror; the incompatibility between the human brain and its mechanical counterpart ultimately results in the destruction of the scientist creator. In this sense, the representation of computers as electronic brains was not a culturally neutral image; on the contrary, it contributed to a connection between the cutting-edge and the grotesque embodied in the isolated brains of contemporary science fiction.

Alongside such representations, the characterisation of computers in humanoid terms was also adopted in some instances to 
facilitate positive engagement with the technology. This was the reasoning behind the adoption of digital computers into election broadcasting from 1952. The inclusion of computers by three different networks in coverage of the 1952 presidential election between Eisenhower and Stevenson was one of the earliest appearances of computers on national television. The use of the Universal Automatic Computer (UNIVAC) by CBS has subsequently been deemed by Cortada (2004, p. 43) as the most 'revealing and dramatic [event] in publicising computers to the American public'. It is essential to explore how UNIVAC was presented as part of this broadcast, in order to analyse how it may have influenced public opinions about computers.

The decision to use UNIVAC was based on practicality and publicity. Computers offered great potential for predicting accurate election outcomes due to their ability to quickly generate largescale calculations based on projected data. However, Sig Mickelson, director of news and public affairs at CBS, suggested that the decision to use UNIVAC extended beyond simply ensuring accuracy:

The novelty value of using UNIVAC was certain to attract attention from both viewers and the print media. 'Computer' was hardly a household word at that time.

[...] I was also aware of the promotional shot in the arm

that the use of the device would give to our coverage.

(Mickelson, 1989, p. 138).

Mickelson's statement implies the computer was used to draw in viewers intrigued by the new technology. Indeed, he made a direct connection between using UNIVAC and ratings by suggesting that it might give the network the 'additional top spin' (Mickelson, 1989, p. 138) it needed to compete with the larger NBC network. This may lend credence to Carroll's (2004) suggestion that despite subconscious emotions of fear or disgust in response to the monstrous, there may also be a level of curiosity that is engaging and attractive.

As hoped by Mickelson, the print media picked up on the use of computers in coverage leading up to the election. Much of this discourse continued to draw on themes of anthropomorphism, demonstrating the continued longevity of this imagery since the launch of ENIAC. The Baltimore Sun (cited in Chinoy, 2010, p. 252) even used the same image of the 'electronic brain' to describe UNIVAC. Advertisements also promised that 'A robot computer will give CBS the fastest reporting in history' (Baltimore Sun, cited in Chinoy, 2010, p. 260), continuing the theme of lauding this technology for its technical capabilities and speed. Simultaneously, internal discussions on televising the computer suggested that producers understood viewers may feel trepidation about the machine. The strategy that was adopted by CBS to counteract this was to deliberately anthropomorphise UNIVAC. It was decided that this would present the computer in a way that was easily accessible for the non-expert viewing audience, with Mickelson (1989, p. 139) acknowledging:

We decided to humanise it, to treat it gently and semihumorously but at the same time give full attention to the data it would produce. That would minimise the risk and would also appease an audience that we speculated might not yet be ready for overly rich doses of high technology.

In the case of election reporting, therefore, anthropomorphising the machine was considered a way of making the computer seem less threatening to ordinary Americans. This approach was not restricted to CBS; NBC, which employed the Monrobot in their election reporting, nicknamed the machine 'Mike' and talked of its character as if it was just another team-member:
Mike's real name is Monrobot and naturally he has a great head for figures. His electronic grey-matter perks so fast that Mike needs a cooling system to keep him from working up a sweat. He weighs 1000 pounds and won't lose an ounce despite constant effort all night long. (cited in Chinoy, 2010, p. 269).

The reference to the computer's 'electronic grey-matter' demonstrates the continued longevity of the electronic brain image. Moreover, it is significant to note that for both networks the prevailing image of the computer in the build-up to election night was of a machine that was powerful but also humanised and, therefore, non-threatening. The computers were to be helpful assistants, working hard at the service of human operators, but never alarming viewers with advanced technical capabilities. This presentation reaffirmed the instrumental conception of the computer and its users, with the former acting solely as a tool to assist the latter.

The presence of anthropomorphism in representations of early computers in the US was a defining feature of the public discourse and its use in different contexts points to conflicting attitudes towards the relationship between computers and users. In some representations, the electronic brain embodied conceptions of cyborgs and humanoid machines, triggering discomfort through the erasure of established boundaries. In other instances, anthropomorphising the machine was a way of re-establishing its position in relation to users as non-threatening, thereby reinforcing an instrumental role. Nevertheless, it is possible to identify themes of monstrosity through the focus on hybridity. The computer could appear as a modern-day Frankenstein's monster, a being existing halfway between subject and object and, moreover, with the perceived potential for further testing of the boundaries of the natural order as it developed its own capabilities for intelligence.

The computer as threat. The episode of computerised election projections using UNIVAC also demonstrated a second key theme in the discourse: anxiety about the relationship between the technology and its users. This manifested in three ways: firstly, casting the computer as servant; secondly, positioning the computer as potential rival; and, finally, presenting the computer as fallible object with no autonomy. It may be suggested that all three presentations reflected an attempt to maintain an instrumental technicity between the computer and its operators and thereby reject the potential for co-constitutional narratives.

The characterisation of the computer as servant can be identified in the treatment of UNIVAC on the night of the election broadcast. Presenter Charles Collingwood, who was working with the machine in the studio, maintained the anthropomorphic rhetoric, telling viewers the computer was simply 'sitting there in his corner, humming away' (Henn, 2012). At one point, Collingwood asked the machine directly'Have you got a prediction for us, UNIVAC?' and when it failed to answer the presenter joked that it was 'very impolite' (Henn, 2012). Collingwood's jovial nature encapsulated the directive to humanise the machine; moreover, it cast UNIVAC in the role of assistant in the election reporting. In reality, the viewers were watching an illusion. The actual UNIVAC machine was at Remington Rand headquarters in Philadelphia; the device shown in the studio was merely a teletype machine (Alfred, 2010). This may suggest a key part of CBS's presentation was to show the computer in relation to Collingwood, both operating in the studio as part of the same 'team', rather than having the computer exist solely off-screen as a mystifying object. Such interactions reassured viewers that the role played by UNIVAC was as an assistant; it was presented as functional and efficient but had no 
personal autonomy. The presentation relied on the instrumental definition of technology, as a tool employed by a user to fulfil a specific need. Moreover, given that the instrumental conception of technology implies the possibility of mastery on the part of the user, by emphasising the functional role played by the computer CBS reinforced its representation as inherently subordinate to its human operators.

Behind the scenes, however, another dimension to this technicity emerged: a sense of competition between man and machine. This conception of the computer as rival to human autonomy characterised not only the presentation of UNIVAC on election night, but also extended beyond the studio. One of the most notable elements of the election reporting by UNIVAC is the fact that the initial prediction made by the computer opposed all pre-election forecasting. The computer made its first prediction at 8:30 p.m., at which point only $5 \%$ of the total vote was known. UNIVAC predicted that Eisenhower would win by a landslide, but this was a complete contrast to all predictions made by forecasters before the election, which predicted a narrow victory for Stevenson (Chinoy, 2010, p. 9). UNIVAC's programmers feared the computer had miscalculated and were reluctant to risk reporting an erroneous result live on the broadcast (Henn, 2012). As a result, the engineers delayed reporting the prediction for two hours; it was not until $10: 30 \mathrm{pm}$, after additional calculations, that the prediction was finally broadcast (Chinoy, 2010, p. 376). Ultimately, UNIVAC's original prediction turned out to be accurate to within four Electoral College votes, with just a 3\% margin of error in the popular vote (Cortada, 2016, p. 25). The early prediction placed the computer in direct opposition to human experts and it is notable that the engineers initially believed it was the computer which had erred. One UNIVAC engineer later acknowledged this, revealing that 'Unfortunately, some of us had more confidence in the Gallup Poll prediction than in the UNIVAC extrapolation, and decided that the machine could not possibly be right' (Vincent, cited in Chinoy, 2010, p. 395). Post-election reviews also indicated tension in this relationship, with New York Times reporter Jack Gould (1952, p. 31) calling UNIVAC 'more of a nuisance than a help'. 'At the critical moment,' Gould (1952, p. 31) wrote, '[UNIVAC] refused to work with anything like the efficiency of the human being.' Consequently, despite the acclaim for UNIVAC's technical abilities in the pre-election broadcasting and the attempt to cast it simply as an assistant, the reality of the relationship between computer and operators was far more complex. It suggested a sense of tension in terms of mastery, perhaps signifying the instrumental categorisation of the computer as a machine was perceived to be at risk.

The fractious relationship between man and machine continued to be part of the discourse surrounding early computers as they became more established in election reporting following 1952. In particular, the anxiety hinted at in the UNIVAC delay escalated into a sense of competition. In the next presidential election in 1956, ABC pitted experienced pollster Lou Harris against the ELECOM in a televised challenge titled 'Man vs. Machine' (Henn, 2012). Following this, Director of the Bureau of the Census Richard Scammon challenged NBC to match him against a computer in projecting their election results, claiming he could produce an accurate result with the same speed as the machine (Coleman et al., 1964, p. 419). Despite the acknowledged value of computers as powerful tools for calculations, therefore, the discourse indicated a sense of conflict in their relationship with humanity. The potential for computers to possibly replace human expertise or overtake human intelligence carried a sense of existential threat, as the machines might usurp human autonomy. From this perspective, the threat of rivalry in the discourse may signal fear in response to the computer, thereby fulfilling one of Carroll's (1987) criteria of the monstrous.

Perhaps to counteract such fears, cultural representations of early computers often emphasised the human role in computing through the figure of the operator. This was demonstrated in the appearance of US Navy computer WHIRLWIND on popular CBS series See It Now in 1951. WHIRLWIND was a forerunner for the modern computer, heralding significant enhancements in memory storage, computer programming, and digital graphics (Smith, 1976). Moreover, WHIRLWIND was one of the first computers to appear on primetime American television. Fronted by Edward Murrow, See It Now introduced its viewers to cutting-edge ideas and current affairs. On 16th December 1951, Murrow presented a report on WHIRLWIND as one of the new technically advanced computing machines. This episode reveals a sense that a clear distinction between the machine and its operator was considered reassuring on the part of both the presenter and the viewers. Murrow's initial interactions with WHIRLWIND belied anxiety in addressing the unknown. Despite introducing the report by declaring 'These are the days of mechanical and electronic marvels', he also admitted seconds later that it was with 'considerable trepidation' that he would attempt to 'interview' the machine (CBS, 1951). Notably, he did not explain the reason for his trepidation, suggesting viewers might naturally share in the feeling and did not require an explanation. Similarly, Murrow acted on the part of the non-expert viewer in the exchanges that followed, carefully scripted to address conscious or subconscious apprehensions. The See It Now episode drew clear distinctions between the machine, its expert operator Jay Forrester, and the layman, represented by Murrow. It may be suggested that drawing such distinctions attempted to assert established categorical boundaries between human and machine. Despite Murrow's misgivings, WHIRLWIND did communicate with him directly, flashing 'Hello Mr Murrow' across its oscilloscope screen (CBS, 1951). Murrow acknowledged the impressiveness of this trick, but subsequently enquired 'I assume that, like any delicate, finely tuned piece of machinery, this has a human element?' (CBS, 1951). The phrasing was deliberate, reinforcing an instrumental definition of the computer as a 'piece of machinery' and placing agency firmly on the human operator.

The following exchanges with Forrester, and with Admiral Calvin Bolster, Chief of Naval Research, focused on demonstrating WHIRLWIND's advanced technical capabilities, reinforcing the position of the computer as simply a piece of machinery. Bolster presented it with a question about the fuel consumption and velocity of the Viking rocket and WHIRLWIND printed the response within seconds (CBS, 1951). As if to emphasise the juxtaposition of this capability with a sense of anxiety, however, when Bolster deemed the results 'very good', Murrow-the selfdescribed 'middle man'-admitted 'I didn't understand the question [...] and I don't understand the answer' (CBS, 1951). The conversation reinforced the notion of the computer's context of use as primarily belonging to experts, establishing a greater sense of distance between the layman and the technology. In this way, the discourse may have served to counteract potential anxiety about the computer as an interstitial being or a potential threat to autonomy.

The reassurance of human dominance in the relationship was also reflected in comedic representations of computers. In some cultural representations, the lack of autonomy and subsequent limitations of the computer served as a means to laugh at the machines. It may be suggested that such presentations worked comedically because they presented the computer as inherently fallible, reasserting human autonomy and a master-servant relationship. By nullifying any potential threat posed by the computer, such representations presented a computer that was 
not so much monstrous as amusing. One example of the fallible computer was the appearance of UNIVAC in cartoon form in a television episode of Warner Brothers' (1952) Merrie Melodies series entitled 'To Hare Is Human'. Labelled as the 'UNIVAC Electronic Brain: Do-It-Yourself Kit', the machine formed the heart of the plotline as Wile E. Coyote attempted to trap his nemesis Bugs Bunny. After inputting data on Bugs-for example, 'breakfast', 'toaster', and 'carrots'-the computer generated suggestions for how to capture him, such as 'Substitute Hand Grenade for Carrots in Toaster' (Warner Bros., 1952). The relationship between Wile E. and the cartoon UNIVAC was conversational, with the computer making suggestions like 'Well... How About Trying A Booby Trap In The Carrot Patch?' (Warner Bros., 1952). However, every suggestion appeared to backfire on the coyote. Finally, as a rock began to fall on Wile E., he ran to the computer to input 'Rock Falling, What'll I Do?'; UNIVAC responded with 'Go Back And Take Your Medicine' and Wile E. dutifully obeyed (Warner Bros., 1952). In the closing moments, it was revealed that Bugs Bunny had been sabotaging the computer from the inside, producing the printouts himself. As he was revealed, Bugs pronounced gleefully 'Of course, the real beauty of this machine is that is has only one moving part!' (Warner Bros., 1952).

The episode, though short, speaks to themes of hybridity and technicity in terms of computers and users. In this representation, the user-Wile E. Coyote-blindly followed the computer's guidance, placing it as the master in the relationship. By relinquishing his own autonomy, both Wile E. and the computer were easily outsmarted by Bugs. The closing punchline highlights that the computer was intended to be seen as humorous because it was unable to think for itself. In the cartoon, the audience was presented with a computer that was only as intelligent as its user; consequently, in any potential conflict between user and technology, it was the 'moving part,' which remained superior. UNIVAC was again presented as comically fallible with a cover story on DC Comics' (1961) Superman's Girlfriend Lois Lane titled 'The Perfect Husband'. In the story, the cartoon host assured Lois that 'Our UNIVAC computer has screened the applications of thousands of bachelors and selected your ideal husband!' However, the match produced by the computer was not Clark Kent, but rather a double, Roger Warner, who turned out to be not as perfect as promised by the computer. Just as in Merrie Melodies, UNIVAC was deliberately presented as fallible, and this fallibility offered the opportunity to laugh at the machine.

To understand how this humorous element aligns with conceptions of the computer as monstrous, it is helpful to consider the close relationship between horror and humour (Solomon, 2003). From a literary and filmic perspective this relationship has been interpreted both as a 'comic turn' in Gothic literature (Horner \& Zlosnik, 2005) and as a distinct genre termed 'horror-comedy' (Carroll, 1999). For Horner and Zlosnik (2005) the 'juxtaposition of incongruous elements' in the Gothic creates space for the comic; in other words, the 'play on boundaries' that is inherent in the literary genre creates a sense of the absurd and uncanny. The effect may be to counterbalance the horror with humour; 'horror-comedy', according to Carroll (1999, p. 145), is 'predicated upon either getting us to laugh where we might ordinarily scream, or to scream where we might typically laugh'. While examples such as 'To Hare Is Human' and 'The Perfect Husband' are perhaps not horrors, the fact that the audience is supposed to laugh at the computer-a potentially monstrous machine-may correlate with Carroll's characterisation of horrorcomedy. Such representations help to nullify the sense of the computer as a threat by instead highlighting its mistakes, making it more amusing than frightening. While the discourse surrounding early computers may incorporate a sense of rivalry, therefore, this should be considered as more complex than purely technophobic.

The computer as curiosity. Despite the prevalence of 'monstrous' elements in discourse surrounding early computers, cultural representations also reflected popular fascination with them. The language used in public appearances of ENIAC, UNIVAC, and WHIRLWIND incorporated images of magic alongside the anthropomorphism, thus imbuing them with a sense of mystique. This may demonstrate how the computer can be linked to another facet of monstrosity: human curiosity in the exotic.

Positive connotations of the computer emerged in characterisations of it as a fantasy creation or mystical machine. Martin's (1993) overview of the language in presentations of ENIAC highlights the prevalence of terms relating to wonder and awe. The Philadelphia Inquirer (cited in Martin, 1993, p. 14) called it the 'Army's New Wonder Brain', while the New York WorldTelegram (cited in Martin, 1993, p. 14) dubbed it a 'Magic Brain'. The implications of such language cast the computer as a fantastical creation from its earliest public representations. In doing so, it was characterised as heralding entry into a new world, with the New York Times (Kennedy, 1946, p. 1) claiming that the 'new electronic speed marvel' would 'revolutionise modern engineering' and Eckert (cited in Kennedy, 1946, p. 16) affirming that 'The old era is going, the new one of electronic speed is on the way'. As such, the discourse encompassed these elements of fascination alongside the stimulation of fears and anxieties.

Murrow (CBS, 1951) echoed this in his description of 'the days of mechanical and electronic marvels' preceding his exchange over WHIRLWIND. When asked to set his own problem to the computer, Murrow asked:

Let's suppose that back in 1626, I'd been an Indian, and I'd received for the sale of Manhattan Island, say, \$24. And if I'd been out covering the story for TV and then I'd 20 invested that $\$ 24$ at six per cent interest, back in 1626 , what would I have today? (CBS, 1951).

Forrester demonstrated how WHIRLWIND would calculate the answer, showing the slips that were fed into the machine and its many storage tubes, before an answer appeared on the typewriter. The result was calculated as $\$ 4,027,727,000$ - and some odd cents' (CBS, 1951). In response, Murrow laughed and deemed the whole exchange to be 'very fascinating' (CBS, 1951). Such interactions support the validity of Carroll's (2004) suggestion that monsters inspire curiosity alongside fear and disgust, and that this curiosity inspires feelings of fascination. Furthermore, the decision of CBS to produce a segment focusing on WHIRLWIND implies a level of public interest in computers. This may be paralleled with the decision of three networks to include computers in election forecasting. Mickelson's (1989, p. 138) explanation of the decision to employ UNIVAC highlighted that producers strongly considered the 'promotional shot in the arm' that the network would get by using it.

Fascination with these computers despite negative affective responses may align with Nye's (1996) conception of the technological sublime in the US. Although Nye (1996) suggests there was growing ambivalence towards the technological sublime in the post-war US in favour of commercialism, the example of early computers perhaps demonstrates the persistence of what he identifies as an American cultural tendency towards technological wonders. Perhaps the most characteristic element of the discourse in response to early computers is, therefore, the establishment and maintenance of a dichotomy of fear and fascination. Such a dichotomy has been characterised as an element of the American tendency to cast technology in sublime terms (Kasson, 1999; 
Marx, 1964). In this sense, the computer may be contextualised as part of the trajectory of innovations that were perceived as not only scientifically significant, but also culturally significant to the American self-identity. However, the American technological sublime outlined in Kasson's (1999) work on the eighteenth- and nineteenth-century US indicates an embrace of the sublime on the condition that the technology serves a purpose for the American people. As a result, the computer may have fulfilled certain elements of the technological sublime, but may also have been considered as divergent. Although early representations sought to emphasise an instrumental definition, the very nature of the computer and its potential for artificial intelligence positioned these examples as more of a potential threat to American autonomy than other machines.

It was this duality that made the computer a popular feature in contemporary works of American science fiction. Following the original EPICAC story published in 1950, Vonnegut's (1952) sentient computer appeared in Player Piano, in which it was not just an object but a character, responding to humans around it on equal terms. Vonnegut (cited in Playboy, 1973) acknowledged that Player Piano was an effort to explore the increasing automation of society, by incorporating the computer as subject rather than just object. This was similar to the inclusion of robot characters in films such as Forbidden Planet (Wilcox, 1956), and television series including My Living Doll (Chertok, 1964), Lost in Space (Allen, 1965), and The Jetsons (Hanna-Barbera, 1962). Frequently the computerised character occupied the assistant role; for example, Rosie the Robot in The Jetsons was employed as the family's housemaid. In other instances, the subservience of the computer to the human operator was used as a plot point, as in the narrative set-up for the B-9 robot in Lost in Space. Regardless of the narrative role of the computer, its inclusion as a character in its own right reflected contemporary interest in the relationship between humans and machines and offered a means to explore this relationship on a cultural level.

Authors such as Arthur C. Clarke and Isaac Asimov employed the computer as both a symbol of futurism and as an integral part of techno-political systems. Asimov, for example, created the fictional computer Multivac that subsequently appeared in a number of his novels. Perhaps most notable of these is its appearance in Franchise (Asimov, 1959), in which the computer is employed to form a government based on the perspective of just one 'most representative person'. First published in 1955, it is hard to avoid parallels with the use of computers in the 1952 presidential election predicting results based on projected data. In Clarke's The City and the Stars (1956), published the following year, the entire city of Diaspar is operated by one 'Central Computer', which creates the city's inhabitants and stores their memories upon their deaths. In both cases, the computer is positioned in a role of power, closely related to political systems in a manner that recalls Hayles' (2012) conception of technogenesis. In 1964, in Profiles of the Future, Clarke (2013) would go on to suggest that a supercomputer was the ultimate realisation of Wells' 'World Brain', capable of absorbing, processing, and using limitless information. This prediction indicated a fascination with the computer's potential capabilities and the extent to which it might be able to exert its power over everyday life, beyond the realms of fiction.

Considering the construction of the computer's image as simultaneously fearsome and fascinating, it is perhaps understandable how such a machine could subsequently become a compelling villain in science fiction of later decades. By the 1960s and 1970s, when the computer's context of use expanded to include areas such as offices and schools, literary and filmic representations of the computer frequently used its innate monstrous qualities to cast it as villainous. In some instances, such as Ellison's (2014) 'I Have No Mouth, and I Must Scream' in 1967 and Koontz's (1997) Demon Seed in 1973, the villainy was grounded in the blurring of biological and mechanical lines. Ellison's monstrous Allied Mastercomputer, or 'AM', alters the physicality and mentality of its human counterparts, while Koontz's 'Proteus' computer is capable of impregnating a human woman. Such representations can be seen as extending the cyborgian discourse associated with early computers to create fictional villains grounded in real fears and fascinations about artificial intelligence. Other examples drew on anxieties and interest in the growing autonomy and independence of thinking machines, including HAL-9000 in 2001: A Space Odyssey (Kubrick, 1968) and Colossus in Colossus: The Forbin Project (Sargent, 1970). In these cases, the computers' villainy centred on their gradual assumption of humanoid tendencies and subsequent capability to threaten human autonomy, and it is notable this fictional exploration of the interstitial nature of the computer drew audiences in. Furthermore, the longevity of the popularity of computerised villains underscores how the monstrous qualities of computers were particularly compelling, with the American Film Institute (2003) naming HAL-9000 as one of the top film villains of the twentieth century. This indicates the extent to which the connections between computers and monstrosity established in responses to early computers like ENIAC, WHIRLWIND, and UNIVAC, would continue to have a cultural impact even as the context of use of computers evolved in later decades.

The example of the computer in the 1950s US perhaps demonstrates how apparently monstrous qualities could also invite curiosity and ignite the interest of popular audiences. The computer had a mystique around it due partly to the fact that it was largely inaccessible and incomprehensible. Simultaneously, its occupation of the interstitial space between animate being with cognitive capabilities and inanimate instrumental tool characterised it as ineffable, an exotic creation outside the realm of understanding. These qualities, combined with the potential threat posed by its capacity for artificial intelligence, may explain how the computer became one of the most fearsome yet fascinating 'monsters' of mid-twentieth-century American culture.

Computers: the ultimate mechanical monsters? Although connections between monstrosity and technology may be identifiable in several instances in the Cold War US, it may be argued that the computer represented a unique case in terms of the discourse. A key element that differentiated it from other contemporary technologies was its interactive nature. Instead of a clear delineation between user and machine, computers represented real potential for this line to become blurred or perhaps even erased. As a result, the potential for hybridity was much greater in the case of computers than other technologies. In this sense, the computer challenged established notions of technicity that clung to instrumental characterisations of technology. By occupying the interstitial space between animate being and inanimate object, the computer was more 'impure' (Douglas, 2002) than other technologies, and it was this impurity that made it monstrous.

It should be noted that this conception of monstrosity was grounded more in representations and perceptions of computers than in reality, for during this period its context of use remained outside the popular sphere. This highlights the role of the computer in capturing Heidegger's (1977) 'essence' of technology, encapsulated in the way people thought about it rather than in its mechanics. Computers posed a particular challenge in this regard because they were so interconnected with other technologies and were lauded as having life-changing potential in the future. This 
implied the relationship with this technology might continue to evolve, continually threatening established boundaries between the natural and the unnatural. Computers were inherently a futurist machine, with their potential forming a consistent part of technological futuregazing and contributing to the notion that the next stage of evolution would be the integration of humans and machines (Pilsch, 2017). However, scientists involved in computing voiced concerns about such potential shifts in technicity. Dr Robert Emrich likened his work in computing to guiding a plough drawn by a tiger. 'As long as the tiger moves forward I am pleased at the progress being made,' he told the Columbia University School of Engineering in 1964. 'But what happens when the tiger turns around and fixes his eyes on me?' (as cited in Seligman, 1966, p. 304). Emrich captured the sense of fear connected to computer proliferation during this period; the security inherent in being the master in the relationship seemed increasingly threatened as this relationship evolved.

As Edwards (1996) has noted, the notion of security was particularly influential in the period of the Cold War, and it cannot be ignored that the historical context lent additional weight to the cultural influence of computers. In this sense, the relationship between technology and society in this period can be characterised as more cyclical than purely determinist; the ties between technological prowess and geopolitical power were so tightly intertwined that it is difficult to attempt to determine cause-and-effect. The computer was not a politically neutral object; it was intrinsically connected to geopolitical technological projects such as the nuclear arms race and the Space Race, ensuring its development had significant implications for national security and prestige.

Early computers like ENIAC, UNIVAC, and WHIRLWIND were not fully fledged cyborgs existing as singular biomechanical organisms, nor were they the robotic sentient beings of science fiction. However, the fact that cultural representations of these machines drew on such rhetoric so consistently was an important factor in shaping cultural attitudes towards them. As Martin (1993) has noted, the primary means of ordinary Americans learning about computers was through public discourse. This discourse established a clear dichotomy of fear and fascination: fears of a loss of autonomy and usurpation of labour, and fascination with a machine that possessed unlimited possibilities. What made the computer truly a mechanical monster was its hybridity, which was perhaps more present in representations of the computer than in the mechanics of the technology itself. It represented both the technological sublime and an apocalyptic dystopia at the same time. Through the combination of existential threat, categorical impurity, and exotic fascination, the computer emerged as a contemporary image of the mechanical monster.

\section{Data availability}

All data generated or analysed during this study are included in this published article.

Received: 28 November 2019; Accepted: 28 October 2020; Published online: 23 November 2020

\section{References}

Alfred R (2010) Nov. 4, 1952: Univac gets election right, but CBS balks. https:// www.wired.com/2010/11/1104cbc-tv-univac-election/\#. Accessed 1 Oct 2019 Allen I (1965) Lost in space. 20th Century Fox

American Film Institute (2003) AFI's 100 years... 100 heroes \& villains. https:// www.afi.com/afis-100-years-100-heroes-villians/. Accessed 23 July 2020

Asimov I (1959) Earth is room enough. Bantam Books, New York
Associated Press (1946) Mechanical Einstein calculator has mathematical world in palm. [news clipping]. Grace Murray Hopper Collection. Smithsonian Institution, Washington, DC

Atomic Heritage Foundation (2019) Double-edged sword. https://atomicheritage org/tourstop/double-edged-sword\#.Xd5i2ej7SUk. Accessed 23 Oct 2019

Boyle H (1949) Machines are laughing at men. [newspaper]. The Evening Independent. https://news.google.com/newspapers?id=LPhPAAAAIBAJ\&sjid=gl UDAAAAIBAJ\&pg $=5992 \% 2 C 5416204$. Accessed 16 Oct 2019

Carroll N (1987) The nature of horror. J Aes Art Crit 46(1):51-59

Carroll N (1999) Horror and humor. J Aes Art Crit 57(2):145-160

Carroll N (2004) The philosophy of horror; or, paradoxes of the heart. Routledge, New York

CBS (1951) Edward Murrow's 'See It Now'-Jay Forrester and the Whirlwind Computer. [video] MIT. https://infinitehistory.mit.edu/video/edwardmurrows-see-it-now\%E2\%80\%94jay-forrester-andwhirlwind-computer- 1951. Accessed 23 Oct 2019

Chertok J (1964) My living doll. CBS Films

Chinoy I (2010) Battle of the brains: Election-night forecasting at the dawn of the computer age. [doctoral dissertation]. http://drum.lib.umd.edu/bitstream/ 1903/10504/1/Chinoy_umd_0117E_11395.pdf. Accessed 4 Sept 2019

Clarke AC (1956) The city and the stars. Houghton Mifflin Harcourt, Boston

Clarke AC (2013) Profiles of the future: An inquiry into the limits of the possible. Hachette, London

Coleman J, Heau E, Peabody R et al. (1964) Computers and election analysis: The New York Times project. Pub Op Quart 28(3):418-446

Cortada JW (2004) The digital hand: How computers changed the work of American manufacturing, transportation, and retail industries. Oxford University Press, Oxford

Cortada JW (2016) The computer in the United States: From laboratory to market, 1930-60. Routledge, Abingdon

Cowan RS (1985) More work for mother: The ironies of household technology from the open hearth to the microwave. Basic Books, New York

DC Comics (1961) The perfect husband. Superman's Girlfriend Lois Lane 1(24). http://www.computerhistory.org/revolution/early-computer-companies/5/ 102/446. Accessed 25 Mar 2020

Dormehl L (2016) Thinking machines: The inside story of artificial intelligence and our race to build the future. WH Allen, London

Douglas M (2002) Purity and danger: An analysis of concepts of pollution and taboo. Routledge Classics, London

Edwards PN (1996) The closed world: Computers and the politics of discourse in Cold War America. MIT Press, Cambridge

Eisenhower DD (1961) Military-industrial complex speech. [transcript] Lillian Goldman Law Library, Yale Law School. https://avalon.law.yale.edu/ 20th_century/eisenhower001.asp. Accessed 2 Sept 2019

Ellison H (2014) I have no mouth \& I must scream: Stories. Open Road Media, New York

Ellul J (1962) The technological order. Tech Cult 3:394-421

Ellul J (1964) The technological society (trans. Wilkinson J). Vintage Books, New York

Evans CL (2018) Broad band: The untold story of the women who made the internet. Portfolio/Penguin, New York

Feagin S (1992) Monsters, disgust and fascination. Phil Stud 65(1/2):75-84

General Electric Theater (1957) Retro classic TV commercial-1950s-live better electrically (GE Theater). [video clip]. https://youtube.com/watch? $\mathrm{v}=$ Z5KEu5WvdnE. Accessed 18 Sept 2019

Gleick J (2011) The information: a history, a theory, a flood. HarperCollins, London

Gould J (1952, Nov 7) Radio and television: C.B.S. television coverage of election returns resulte in landslide victory for network. New York Times

Green J (1962) The brain that wouldn't die. American International Pictures

Hanna-Barbera (1962) The Jetsons. Screen Gems

Haraway D (1985) A cyborg manifesto: Science, technology, and socialist-feminism in the late 20th century. Soc Rev 80:65-108

Hart H (1946) Technological acceleration and the atomic bomb. Am Soc Rev $11: 277-293$

Hayles NK (2012) How we think: Digital media and contemporary technogenesis. University of Chicago Press, Chicago

Heidegger M (1977) The question concerning technology and other essays (trans. Lovitt W). Garland Publishing, New York

Hendricks N (2018) Popular fads and crazes through American history. Greenwood, Santa Barbara

Henn S (2012) The night a computer predicted the next president. https://www. npr.org/sections/alltechconsidered/2012/10/31/163951263/the-night-acomputerpredicted-the-next-president $\mathrm{t}=1574632309741$. Accessed 24 Oct 2019

Horner A, Zlosnik S (2005) Gothic and the comic turn. Palgrave Macmillan, Basingstoke 
Kasson JF (1999) Civilizing the machine: Technology and republican values in America. Farrar, Straus and Giroux, New York, pp. 1776-1900

Kellner T (2019) Lights, electricity, action: When Ronald Reagan hosted "General Electric Theater". General Electric Reports. https://www.ge.com/reports/ ronald-reagan-ge/. Accessed 23 Oct 2019

Kennedy TR (1946, Feb 15) Electronic computer flashes answers, may speed engineering. [newspaper]. New York Times 1, 16. https://nytimes.com/1946/ 02/15/archives/electroniccomputer-flashes-answers-may-speed-engineeringnew.html. Accessed 23 Sept 2019

Kirschenbaum MG (2016) Track changes: A literary history of word processing. Harvard University Press, Cambridge

Koontz D (1997) Demon seed. Headline, London

Kranzberg M (1986) Technology and history: 'Kranzberg's Laws'. Tech Cult 27 (3):544-560

Kubrick S (1968) 2001: A space odyssey. Metro-Goldwyn-Mayer (MGM)

Latour B (2002) Morality and technology (trans. Venn C). The Cult Soc 19(5/ 6):247-260

Lawrence D (1953, Oct 12) Hysteria about H-bomb. St. Petersburg Times

Lawrence N (2015) What is a monster? https://cam.ac.uk/research/discussion/ what-is-a-monster. Accessed 25 Mar 2020

Martin CD (1993) The myth of the awesome thinking machine. Comms ACM 36 (4):120-133. https://doi.org/10.1145/255950.153587

Marx L (1964) The machine in the garden: Technology and the pastoral ideal in America. Oxford University Press, New York

Mechanix Illustrated (1946) The army brain. [magazine article]. Modern Mechanix. http://blog.modernmechanix.com/the-army-brain. Accessed 12 Sept 2019

Mickelson S (1989) From whistle stop to sound bite: Four decades of politics and television. Praeger, London

Nye DE (1996) American technological sublime. MIT Press, Cambridge

Oudshoorn N, Pinch T (2005) How users matter: The co-construction of users and technology. MIT Press, Cambridge

Pilsch A (2017) Transhumanism: Evolutionary futurism and the human technologies of utopia. University of Minnesota Press, Minneapolis

Pittsburgh Post-Gazette (1945) Banning the atomic bomb. https://www. newspapers.com/newspage/87715542. Accessed 15 Nov 2020

Playboy (1973) Playboy interview, Kurt Vonnegut, Jr. Playboy Magazine

Pötzsch H (2014) Posthumanism, technogenesis, and digital technologies: A conversation with N. Katherine Hayles. http://twentythree.fibreculturejournal. org/fcj-172-posthumanism-technogenesisand-digital-technologies-aconversation-with-katherine-n-hayles/. Accessed 25 Mar 2020

Sargent J (1970) Colossus: The Forbin project. Universal Pictures

Seligman BB (1966) Most notorious victory: Man in an age of automation. Free Press, London

Smith TM (1976) Project Whirlwind: An unorthodox development project. Tech Cult 17:447-464
Solomon RC (2003) Real horror. In: Schneider SJ, Shaw D (eds) Dark thoughts: Philosophic reflections on cinematic horror. Scarecrow Press Inc, Lanham MD, pp. $230-259$

Staudenmaier J (1984) What SHOT hath wrought and what SHOT hath not: Reflections on twenty-five years of the history of technology. Tech Cult 25 (4):707-730

Vonnegut K (1950, Nov 25) EPICAC. Collier's Weekly

Vonnegut K (1952) Player piano. Scribner, New York

Warner Bros. (1952) To hare is human. [video] Big Cartoon Database. https:// www.bcdb.com/cartoon/5230-To-Hare-is-Human. Accessed 22 Sept 2019

Wells HG (2016) World Brain. Read Books, Redditch

Wilcox FM (1956) Forbidden planet. Metro-Goldwyn-Mayer (MGM)

Winner L (1978) Autonomous technology: Technics-out-of-control as a theme in political thought. MIT Press, Cambridge

Winner L (1986) The whale and the reactor: a search for limits in an age of high technology. University of Chicago Press, Chicago

\section{Competing interests}

The author declares no competing interests.

\section{Additional information}

Correspondence and requests for materials should be addressed to H.G.

Reprints and permission information is available at http://www.nature.com/reprints

Publisher's note Springer Nature remains neutral with regard to jurisdictional claims in published maps and institutional affiliations.

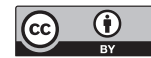

Open Access This article is licensed under a Creative Commons Attribution 4.0 International License, which permits use, sharing, adaptation, distribution and reproduction in any medium or format, as long as you give appropriate credit to the original author(s) and the source, provide a link to the Creative Commons license, and indicate if changes were made. The images or other third party material in this article are included in the article's Creative Commons license, unless indicated otherwise in a credit line to the material. If material is not included in the article's Creative Commons license and your intended use is not permitted by statutory regulation or exceeds the permitted use, you will need to obtain permission directly from the copyright holder. To view a copy of this license, visit http://creativecommons.org/ licenses/by/4.0/

(C) The Author(s) 2020 